\title{
Optimization of Thickness and Number of Layers for CdTe Films Deposited by Stacked Elemental Layers Method and Annealed in Different Environments
}

\author{
S. H. Moustafa, H. M. Hashem, and A. T. Mater \\ Physics Department, Faculty of Science, Helwan University, \\ Helwan, Cairo, Egypt \\ Email: saidmost@hotmail.com
}

Thin films of CdTe were deposited by stacked elemental layers method on glass substrate. The effect of different evaporation parameters upon the structural and optical properties has been investigated by using X-ray diffraction and optical spectrophotometry measurements. X-ray data were collected and crystal structure analyses were performed using Rietveld refinement method. In the present study the thickness of the films was varied in the range $100-300 \mathrm{~nm}$, additionally the layers were adjusted in range between 3-5 layers. Furthermore, the films were annealed at $200{ }^{\circ} \mathrm{C}$ for 30 minutes in different environments. $X$-ray diffractograms showed that films annealed in vacuum exhibit only a single CdTe phase while multiphase films were obtained for films annealed in air. The results show that decreasing of the film thickness and/or increasing of the number of stacked layers enhances the phase purity of the films. Optical energy gaps $(1.36-1.51 \mathrm{eV})$ were estimated from the manipulation of transmission and reflection data. The analysis of structural and optical data revealed optimum conditions for obtaining high quality films (single phase) that the thickness is $200 \mathrm{~nm}$ and the number of layers is five.

\section{Introduction:}

Cadmium Telluride (CdTe) based solar cells is the promising candidate for photovoltaic energy conversion. This is because of the high potential to realize low cost, high efficiency, reliable and stable solar cells [1]. CdTe has absorption coefficient $>10^{4} \mathrm{~cm}^{-1}$ and optimum band gap of $1.5 \mathrm{eV}$. Furthermore, many deposition techniques have been used to prepare CdTe thin films, such as sputtering [2], electrodeposition [3], vacuum evaporation [4], electrochemical atomic layer epitaxy [5], pulsed laser deposition [6-8] and close-spaced sublimation [9]. Stacked elemental Layers (SEL) technique is suggested to be a commercially realizable method for manufacturing solar cells. 
The SEL is a suitable technique for large area development, simplicity, controlling deposition parameters, and the flexibility in the choice of preparation method of the elemental stacks [10-13].

It was found that the optimum sequence of the layers is $\mathrm{Te} / \mathrm{Cd} / \mathrm{Te}$ and the optimum annealing temperature was $200{ }^{\circ} \mathrm{C}$ for half an hour in air [13]. However, there are many other parameters have to be investigated in order to get a single phase of polycrystalline CdTe thin films. The present work is mainly devoted to study some of these parameters, they are total film thickness, the number of layers and the annealing environment (vacuum and air).

\section{Experimental:}

The layers were deposited by thermal evaporation technique (PVD) using E306A vacuum system. Spec-pure Cd (99.999 \%) and Te (99.9999 \%) were evaporated. The thickness of elemental is adjusted, so that, the number of atoms in $\mathrm{Te}$ and $\mathrm{Cd}$ layers must be identical to get stoichiometric composition. Considering the density and atomic weight of each element, the relation between thickness of layers is specified as $\mathrm{t}_{\mathrm{Te}} / \mathrm{t}_{\mathrm{Cd}}=1.53$ [13]. Three different total thicknesses of 100, 200, and $300 \mathrm{~nm}$ were evaporated on pre-cleaned glass substrates at room temperature. Three layers $(\mathrm{g} / \mathrm{Te} / \mathrm{Cd} / \mathrm{Te})$ and five layers $(\mathrm{g} / \mathrm{Te} / \mathrm{Cd} / \mathrm{Te} / \mathrm{Cd} / \mathrm{Te})$ were deposited with these three different total thicknesses.

The thickness and the deposition rate of the films were controlled using a digital film thickness monitor (FTM4, Edwards, England). The films were annealed at $200{ }^{\circ} \mathrm{C}$ for 30 minutes in different environments (air and vacuum). Computer controlled X-ray diffractometer (Shimadzu-6000, Japan) with monochromatic $\mathrm{Cu}-\mathrm{K}_{\alpha}$ radiation $(\lambda=1.540562 \AA)$ was used for the structural investigation. The scanning range was $10-80^{\circ}(2 \theta)$ with step size of $0.05^{\circ}(2 \theta)$ and counting time of 5 second per step. Peak characteristics (peak position, integrated intensity) were accomplished by the WinFit computer program [14], and whole diffraction pattern fitting by Fullprof computer program of Rietveld method [15]. The optical transmittance (T) and reflectance (R) spectra were recorded at normal incident in the wavelength range of 300-2400 nm, using a double beam spectrophotometer (Type Jasco, V-570).

\section{Results and Discussion:}

It could be noted that all the prepared films show good adhesion on the glass substrate. Effect of the thickness and number of stacked layers as well as the environment of annealing were investigated as follows. 


\subsection{X-ray structure analysis}

\section{A-Glass/Te/Cd/Te}

Firstly, films with three layers deposited at different thicknesses were investigated. The XRD diffractograms of the annealed films in air for different thicknesses (100, 200, and $300 \mathrm{~nm}$ ) are shown in Fig. (1). The simulated diffractogram pattern of CdTe is also included as standard one for comparison. Inspection of results reveals that some films show two phases, CdTe and $\mathrm{Cd}_{3} \mathrm{TeO}_{3}$ beside pure elements $\mathrm{Cd}$ and $\mathrm{Te}$. It is clear from the diffractograms that the diffraction peaks occurred at (111), (220) and (311) can be indexed on the basis of Powder Diffraction Standards Data of CdTe (CDD no. 15-0770) Nevertheless, some additional peaks are observed such as $\mathrm{Cd}_{3} \mathrm{TeO}_{6}$ phase which appeared sharply at $2 \theta=31.7^{\circ}$ in films with thickness $100 \mathrm{~nm}$ (sample No. 13a), and some traces of pure $\mathrm{Cd}$ and Te. Note the oxidation of CdTe films is a result of annealing in air. Fig. (2) depicted the XRD patterns of three layers vacuum annealed films (sample No. 13v). Apparently, all reflection lines are indexed on the bases of the standard CdTe structure. Moreover, as the thickness increases to $200 \mathrm{~nm}$ (sample No. 23v) not only the CdTe phase present but also some weak peaks related to pure $\mathrm{Cd}$ and $\mathrm{Te}$ are observed. It is worth to mention that there is no change in the structure of the films with further increase of the thickness up to $300 \mathrm{~nm}$ (sample No. 33v), but with free $\mathrm{Cd}$ and $\mathrm{Te}$ as well as peaks of $\mathrm{TeO}$ are observed.

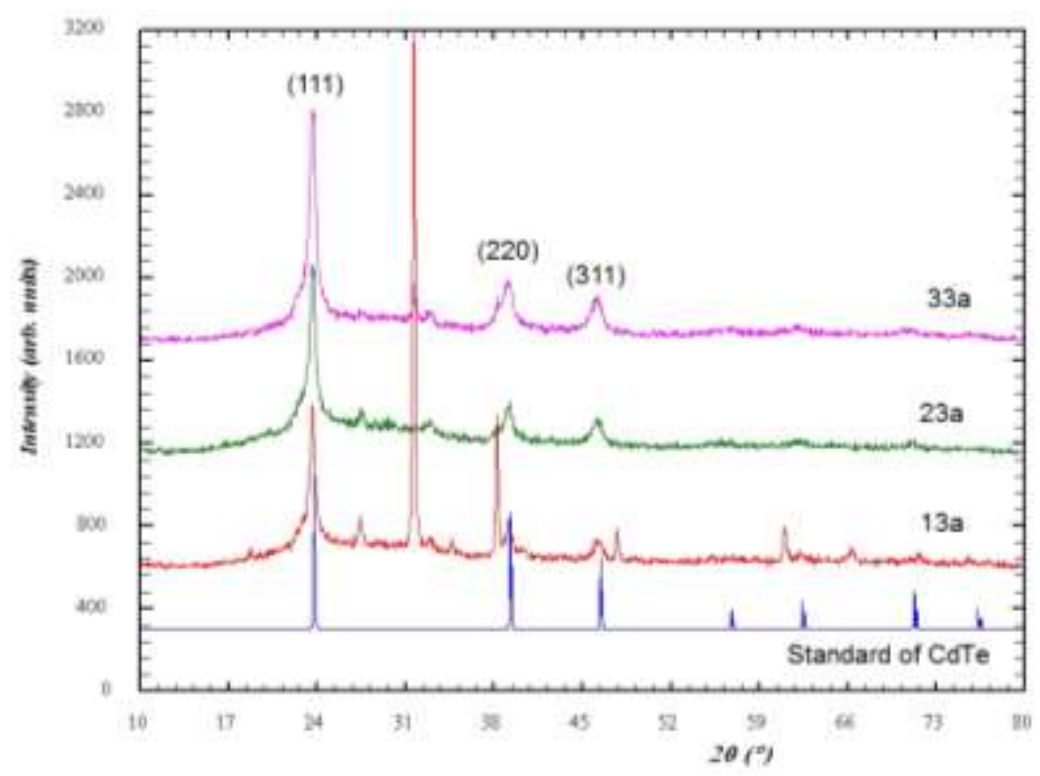

Fig. (1): X-ray diffractogram of films of different thicknesses and five layers annealed in air. 


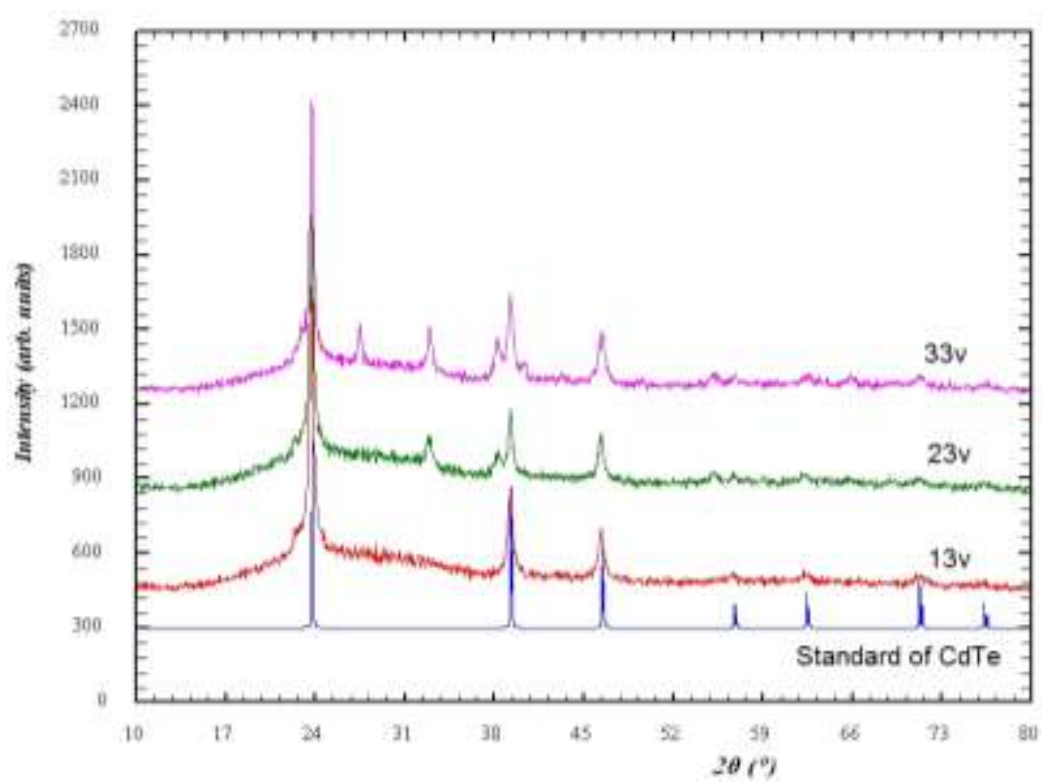

Fig. (2): X-ray diffractogram of films of different thicknesses and three layers annealed in vacuum.

\section{B- Glass/Te/Cd/Te/Cd/Te}

Figure (3) shows XRD patterns of the standard CdTe film in comparison with reflection lines of the films deposited at different thicknesses and annealed in air. The results reveal that all prepared films contain CdTe phase and $\mathrm{Cd}_{3} \mathrm{TeO}_{6}$ phase in addition to pure $\mathrm{Cd}$ and $\mathrm{Te}$ elements. The oxide phase is attributed to the presence of oxygen in air. However, Fig. (4) illustrates the diffractograms of the films deposited at different thicknesses and annealed in vacuum with the same number of layers. The reflection peaks of the films with thicknesses $100 \mathrm{~nm}$ and $200 \mathrm{~nm}$ (samples No. 15v and 25v) show a good agreement with the standard CdTe reflection data. While, some additional lines of pure $\mathrm{Cd}$ and Te elements appeared with increasing the thickness to $300 \mathrm{~nm}$ (sample No. 35v) which may be attributed to the incomplete reaction between $\mathrm{Cd}$ and Te.

Rietveld refinement algorithm [16] was applied to the XRD patterns of sample No. 25v in order to verify the presence of a single CdTe phase and to determine the crystallographic parameters, e. g. lattice constants. The calculations was achieved using a computer program, written by Lutterotti et al. [15] with graphical presentation. The observed and the calculated XRD data together with residual data (lower part in the diagram) are collected in Fig. (5). 
Lattice parameters (of cubic CdTe) $\mathrm{a}=6.48 \AA$ And space group $(\mathrm{F} \overline{4} 3 \mathrm{~m})$ were used as input for Rietveld refinement in addition the Crystallographic information given in the Table (1).

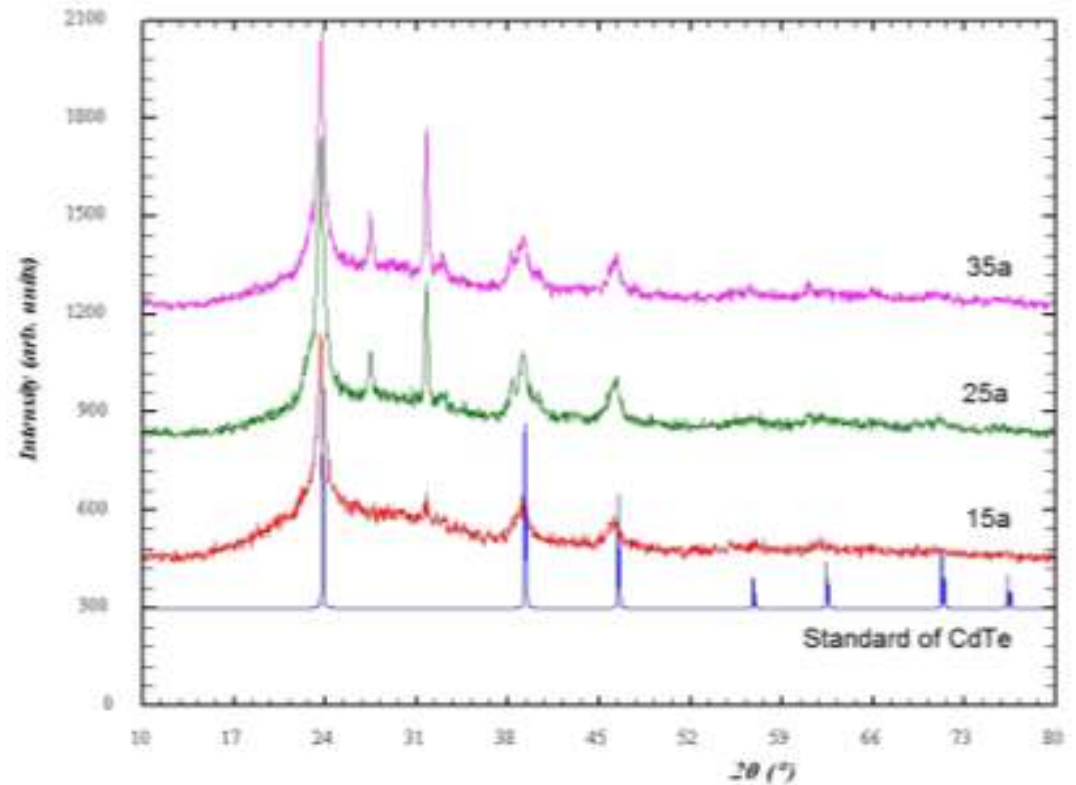

Fig. (3): X-ray diffractogram of films of different thicknesses and three layers annealed in air

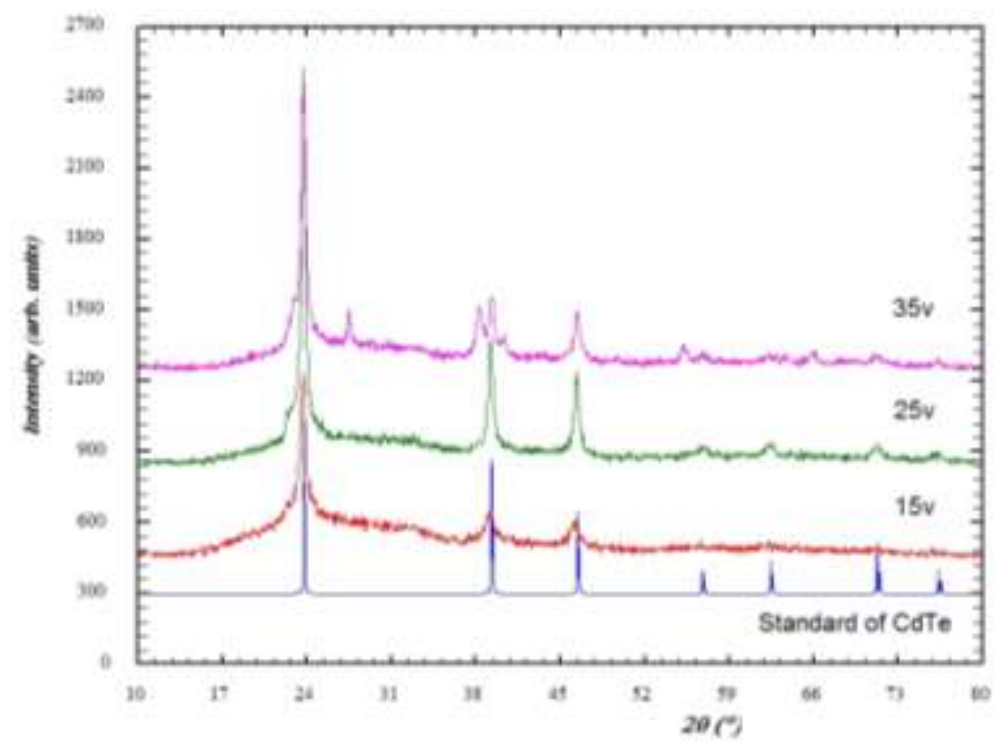

Fig. (4): X-ray diffractogram of films of different thicknesses and three layers annealed in vacuum. 


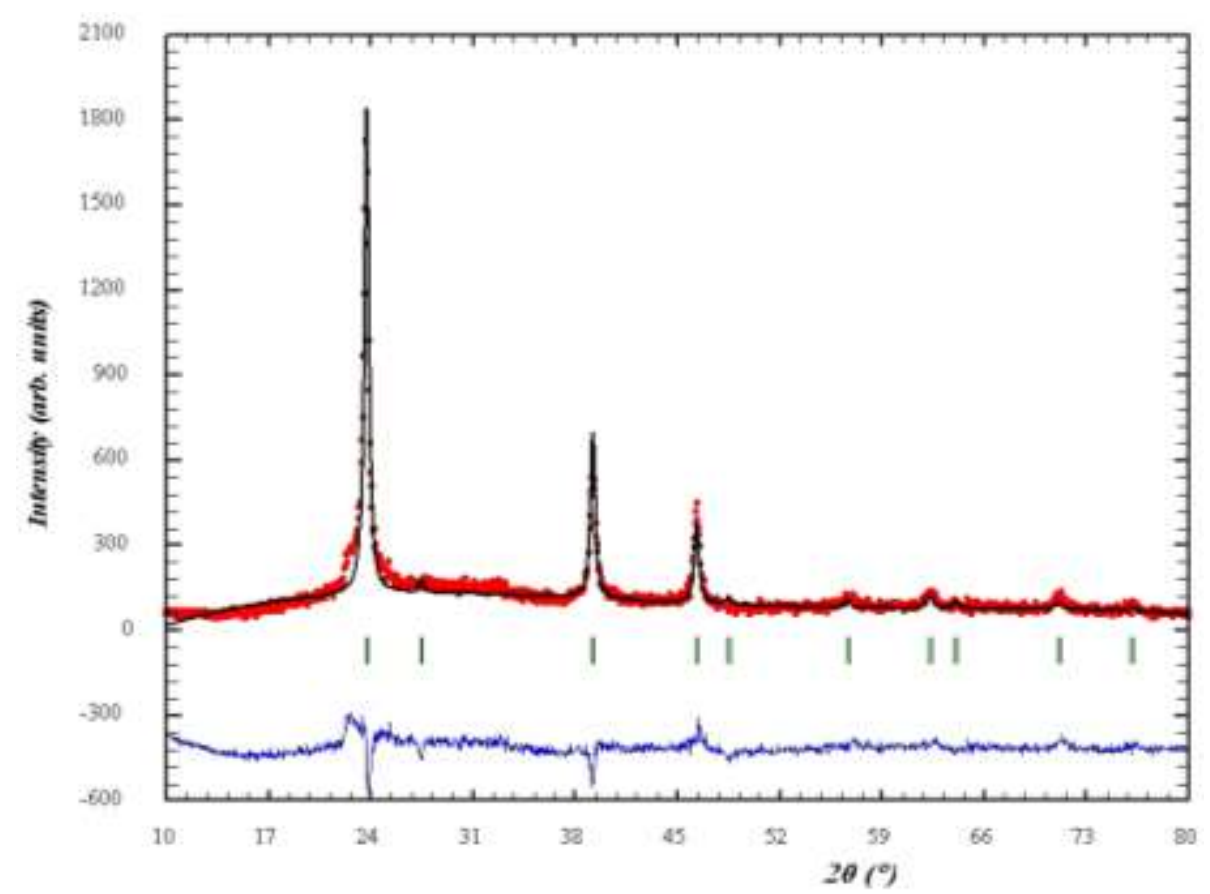

Fig. (5): Rietveld refinement of the diffracted patterns of CdTe 25v sample. $($ Goodness-of-fit $=1.93)$.

Table (1): Crystallographic information of CdTe.

\begin{tabular}{|c|c|c|c|c|c|}
\hline \multirow{2}{*}{$\begin{array}{l}\text { Elemen } \\
\mathrm{t}\end{array}$} & \multicolumn{2}{|c|}{ Fraction coordinates } & \multirow{2}{*}{$\begin{array}{c}\text { Displacement parameter } \\
\text { (Temperature factor) }\end{array}$} & $\begin{array}{c}\text { Occupanc } \\
\mathrm{y}\end{array}$ \\
\cline { 2 - 4 } $\mathrm{Cd}$ & 0.00 & 0.00 & 0.00 & 23.790 & 1 \\
\hline $\mathrm{Te}$ & 0.25 & 0.25 & 0.25 & 9.696 & 1 \\
\hline
\end{tabular}

From the X-ray crystallographic structure investigation, all the samples annealed in air are multiphase. On the other hand, annealing in vacuum enhances the formation of mono phase. Table (2) gives the CdTe peaks extracted from the good (single CdTe phase) samples, such as sample No. 13v, $15 \mathrm{v}$ and $25 \mathrm{v}$. It could be noted that variation of the film thickness reveals that single CdTe phase is obtained at small thickness (100-200 nm). It is also evident that sample quality improved with films obtained with large number of layers with small thickness $(100-200 \mathrm{~nm})$. 
Table (2): X-rays diffraction data of the optimum conditions

\begin{tabular}{|c|c|c|c|c|c|c|c|c|}
\hline \multicolumn{2}{|c|}{ Sample (13v) } & \multicolumn{2}{|c|}{ Sample (15v) } & \multicolumn{2}{|c|}{ Sample (25v) } & \multicolumn{3}{|c|}{ CDD no. $15-0770$} \\
\hline $\mathrm{d}(\stackrel{\AA}{\mathbf{A}})$ & $\mathbf{I} / \mathbf{I}_{0}(\%)$ & $\mathrm{d}(\AA)$ & $\mathbf{I} / \mathbf{I}_{0}(\%)$ & $\mathrm{d}(\AA)$ & $\mathbf{I} / \mathbf{I}_{\mathbf{0}}(\%)$ & $\mathrm{d}(\AA \mathbf{\AA})$ & $\mathbf{I} / \mathbf{I}_{0}(\%)$ & hkl \\
\hline 3.763 & 100 & 3.761 & 100 & 3.753 & 100 & 3.750 & 100 & 111 \\
\hline 2.298 & 43 & 2.303 & 22 & 2.294 & 32 & 2.290 & 60 & 220 \\
\hline 1.956 & 22 & 1.964 & 16 & 1.957 & 23 & 1.955 & 30 & 311 \\
\hline 1.622 & 3 & 1.624 & 2 & 1.617 & 2 & 1.619 & 6 & 400 \\
\hline 1.488 & 6 & 1.488 & 34 & 1.487 & 4 & 1.489 & 10 & 331 \\
\hline 1.323 & 4 & 1.322 & 3 & 1.322 & 3 & 1.323 & 10 & 422 \\
\hline- & - & - & - & 1.248 & 2 & 1.246 & 4 & 511 \\
\hline
\end{tabular}

\subsection{Optical Results:}

The spectral behavior of the transmittance, $\mathrm{T}$, and reflectance, $\mathrm{R}$, at normal incidence of the optimum samples are depicted in Figs. (6-7). Apparently, above the absorption edge, the appearance of interference maxima and minima at the same wavelength indicates the optical homogeneity of the deposited films [17].

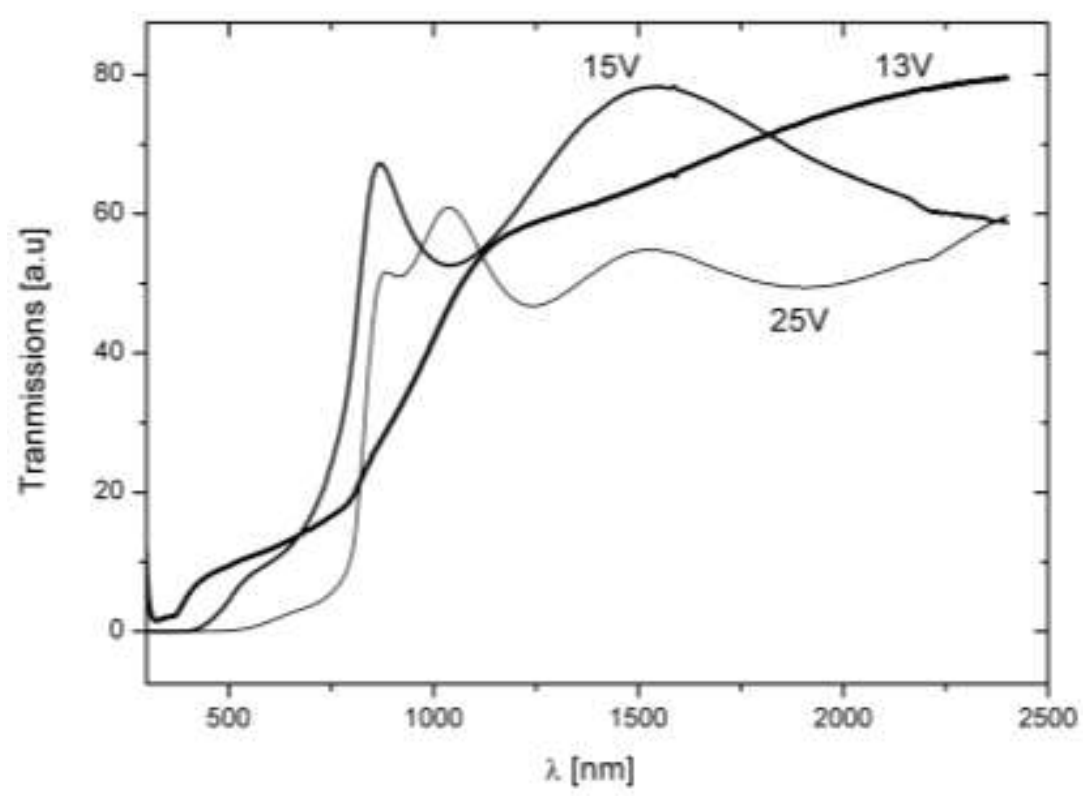

Fig. (6): Transmittance T spectra of the good CdTe samples. 


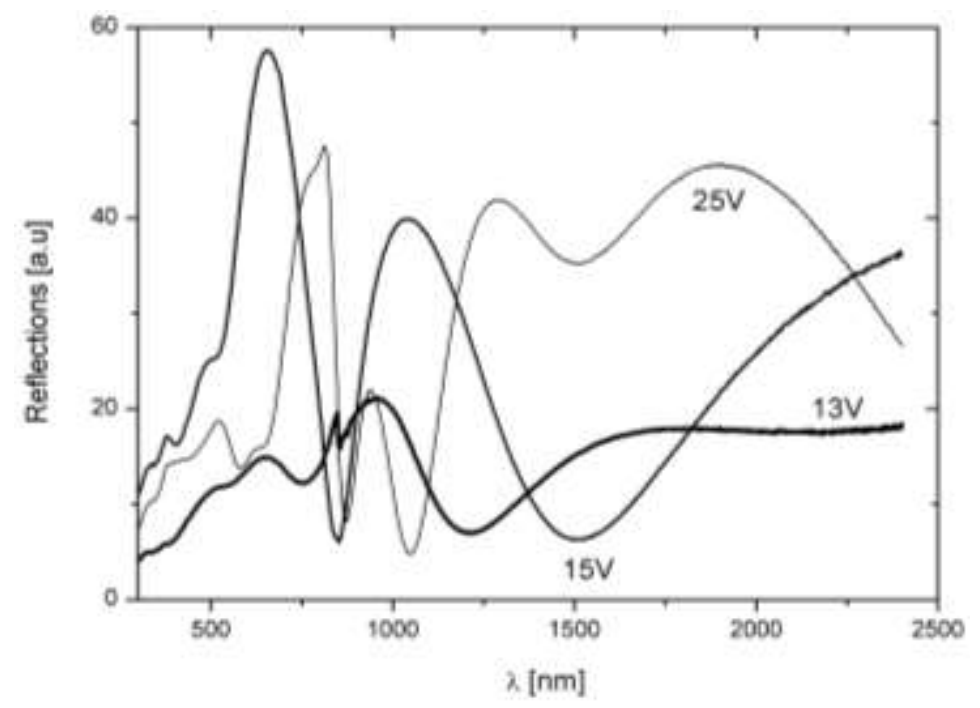

Fig. (7): Reflectance spectra of the good CdTe samples.

Using the measured values of $\mathrm{R}$ and $\mathrm{T}$, the absorption coefficient $\alpha$ was calculated according to the well known equation [18],

$$
\alpha=\frac{1}{d} \ln \left(\frac{(1-R)^{2}}{2 T}+\left(\frac{(1-R)^{4}}{4 T^{2}}+R^{2}\right)^{\frac{1}{2}}\right)
$$

where $\alpha$ is the absorption coefficient and $d$ is the film thickness, the direct energy gap $\left(\mathrm{E}_{\mathrm{g}}\right)[18]$ was extracted from

$$
\alpha=\frac{A}{h v} \sqrt{h v-E_{g}}
$$

where $\mathrm{A}$ is a constant and $h \boldsymbol{V}$ is the incident photon energy. To determine the optical band gap $\mathrm{E}_{\mathrm{g}}$ of the investigated films, $(\alpha h v)^{2}$ versus $h v$ was plotted as shown in Fig. (8). The extrapolation of the linear part of the curves to the photon energy axis would give the optical energy band gap. The results give optical band gap ranging between 1.36 and $1.51 \mathrm{eV}$ (Table 3) which is in fair agreement with those reported in the literature for the CdTe polycrystalline material $(1.5 \mathrm{eV})$ [19]. It should be noted that as the number of layers of the films (for the same thickness) increased the energy gap becomes more close to the value of the CdTe single crystal. 


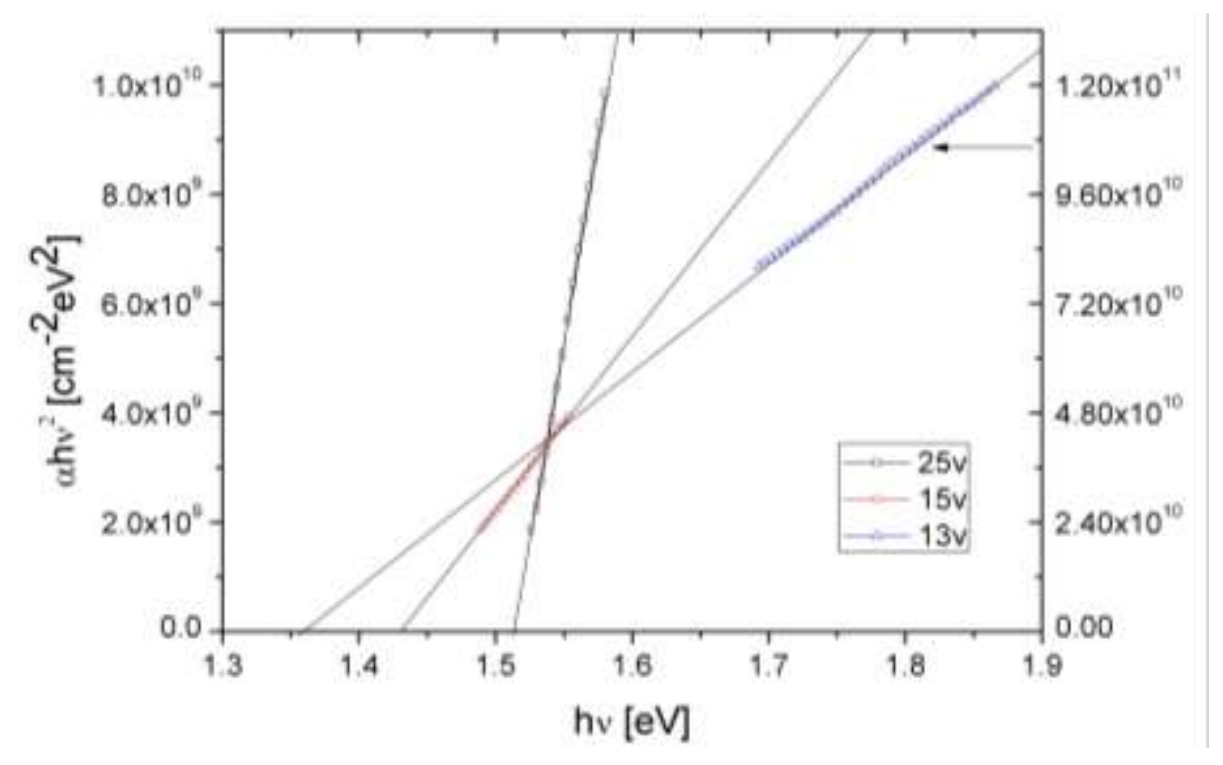

Fig. (8): $(\alpha h v)^{2}$ versus h $v$ for the CdTe samples.

Table (3): Thicknesses and optical gap for the optimum condition of polycrystalline CdTe thin films

\begin{tabular}{|c|c|c|c|}
\hline Sample & Thickness $(\mathrm{nm})$ & Number of layers & Energy gap (eV.) \\
\hline $13 \mathrm{v}$ & 100 & 3 & 1.360 \\
\hline $15 \mathrm{v}$ & 100 & 5 & 1.438 \\
\hline
\end{tabular}

\section{Conclusions:}

With the careful control of the total film thickness as well as layers number and annealing in vacuum, pure single polycrystalline CdTe thin films can be obtained by stacked elemental layers of $\mathrm{Cd}$ and Te. Total film thickness in the range of $100-200 \mathrm{~nm}$ and at least five layers with annealing at $200^{\circ} \mathrm{C}$ for 30 minutes under vacuum enhances the single phase formation. Consequently, a low total film thickness and large number of layers are recommended. Ritveld refinement and optical energy gap are successfully verify the formation of single phase of CdTe with the optimum thickness of about $200 \mathrm{~nm}$ and number of layers $=5$.

\section{Acknowledgment}

The Support of the Science and Technology Development Fund (STDF) Grant ID 377 is greatly appreciated. 


\section{References:}

1. Md. Sharafat Hossain, Nowshad Amin, M.A. Matin, M. Mannir Aliyu, Takhir Razykov, and Kamaruzzaman Sopain, Calcogenide Letters, 8 , (3), 263 (2011).

2. M. B. Das, S. V. Krishnaswamy, R. Petkie, P. Swab, K. Vams, Soild State Electron, 27, 329 (1984).

3. M. P. R. Panicker, M. Knaster, F. A. Kroger, J. Electrochem. Soc., 125, 556 (1978).

4. H. Uda, H. Taniguchi, M. Yoshida, Y. Yamashita, Jpn. J. Appl. Phys., 17, 585 (1978).

5. J. Ramiro, A. Perea, J. F. Trigo, Y. Laaziz, E. G. Camarero, Thin Solid Films, 361, 65 (2000).

6. F. Jackson, L. E. A. Berlouis, P. Rocabois, B. C. Cavenett, J. Cryst. Growth, 159, 200 (1996).

7. Giardini, M. Ambrico, D. Smaldone, R. Martino, G. P. Parisi, V. Capozzi, G. Perna, Appl. Surf. Sci., 106, 144 (1996).

8. J. T. Cheung, M. Khoshnevisan, T. Magee, Appl. Phys. Lett., 43, 462 (1983).

9. A. R. M. Alamoud, Eng. Sci. 2, 211 (2002).

10. Ashour, A. A.Ramadana, K. Abd EL-Hady, A. A. S. Akl, Journal of Optoelectronics and Advanced Materials, 7, (3), 1493 (2005).

11. M. T. Bhatti, K. M. Hynes, R. W. Miles, R. Hill, Int. J. Solar Energy, 12, 171 (1992).

12. R. W. Miles, M. T. Bhatti, K. M. Hynes, A. E. Baumann, R. Hill, Mater. Sci. Eng., B16, 250 (1993).

13. S. H. Moustafa, Egypt J. Solids, 31, (1), 1 (2008).

14. S. Krumn; XIII th Conference on Clay Mineralogy and Petrology, Praha (1994), Acta Universitatis Carolinae Geologica, 38, 253 (1994).

15. L. Lutterotti, P. Scardi, P. Maistrelli, J. Appl. Cryst. 25, 459 (1992).

16. L. B. McCusker, R. B. Von Dreele, D. E. Cox, D. Louer, P. Scardi, J. Appl. Cryst., 32, 36 (1999).

17. A. M. Salem, and S. H. Moustafa, FIZIKA A, 13, 4, 137 (2004).

18. R. E. Denton, R. D. Cambell and S. G. Tpmlin, J. Phys., D 5, 863 (1972).

19. A. A. Abd El-Mongy, A. A. Ramadan, and H. M. Hashem, Phys. Stat. Sol. (a), 202, 10, 1925 (2005). 